\title{
Entrevista com Renato Ortiz
}

\section{Práticas de recepção e a centralidade da cultura}

A temática da cultura tem ocupado atualmente espaço de centralidade nos estudos e pesquisas sobre o processo da recepção mediática.

E é exatamente sobre o campo da cultura que Renato Ortiz tem dedicado, já há longos anos, trabalhos e pesquisas, sendo um dos pioneiros nestes estudos no Brasil e reconhecida autoridade acadêmica.

Com formação em Sociologia e Antropologia, é atualmente professor Titular do Departamento de Sociologia da Unicamp. Tem publicados, no país e no exterior, diferentes textos e artigos, sobressaindo-se seus livros em muitos dos quais faz a aproximação entre cultura e comunicação.

Os excertos a seguir são indicativos de seu pensamento, obtidos quando de debate com membros da equipe de Novos Olhares.

\section{Recepção Ampliada}

NO - A multiplicação dos canais de acesso à televisão amplia quantitativamente a recepção, mas também diminui ainda mais a qualidade da produção?

RO - Eu acho que já acumulamos ao longo dos anos um razoável conhecimento em relação a $\mathrm{TV}$, mesmo que restem reflexões novas a serem feitas. São os públicos alvos do mercado que constituem a base fundamental da programação televisiva, sobretudo da chamada televisão de canal aberto. Dentro dessa perspectiva, a questão da qualidade do programa não é prioritária (o que não significa que não seja importante). Mesmo na TV à cabo encontrase presente a idéia de que os programas tem que ser consumidos por segmentos e que nesses segmentos é necessário ter uma "boa" audiência. A idéia de rentabilidade tem um peso muito grande na elaboração dos programas.

Por outro lado, não há realmente no Brasil uma crítica da produção televisiva. Não temos na grande imprensa uma crítica mais consistente, como existe, por exemplo, a tradição de uma crítica cinematográfica. Eventualmente existem artigos, reflexões pessoais sobre este ou aquele aspecto, mas nada semelhante à uma compreensão mais sistemática e aprofundada sobre o conteúdo dos programas. É óbvio que há uma certa imprensa que se dedica ao tema, penso nessas revistas especializadas em novelas, mas aí temos um tratamento inteiramente mercadológico, cultivandose uma idolatria dos grandes astros.

\section{Mundialização}

NO - Com a expansão generalizada da televisão por todo o mundo, estar-se-ia chegando a uma mundialização não mais só da técnica, mas também da cultura? RO - Não tenha dúvida do seguinte: o processo de mundialização da cultura dissemina um conjunto de parâmetros que se reproduzem em escalas variadas nas diversas sociedades do planeta, em função das histórias de cada uma delas. Neste contexto, eu diria que a telenovela brasileira já se faz parte de um padrão 
mundializado, só que em português. Há o padrão mundializado, feito em inglês, ambos porém são marcados pelas exigências dos mercados nacional e global. O que vai acontecer com as tradições não dominantes (feitas em português, espanhol, etc) no contexto do mercado globalizado, é uma boa pergunta. Eu diria o seguinte: os países que conseguiram construir uma indústria cultural forte dentro do processo de globalização têm alguma capacidade de "negociação" em relação a outros produtos industrializados. Em termos ficcionais, a televisão brasileira ocupa uma posição razoável. Isso lhe dá pelo menos uma vantagem inicial. Temos também um legado musical bastante forte, com boa capacidade de interagir à nível mundial.

NO - Como você se interessou pelo tema da mundialização?

RO - Veja, em 1988 publiquei um livro “A Moderna Tradição Brasileira”- cujo último capítulo chamava-se "Do nacional popular, ao internacional popular”. Pesquisando a indústria cultural, e particularmente a telenovela tive a idéia de falar sobre o "internacional popular". $\mathrm{Na}$ pesquisa empírica que fiz na TV Globo e na TV Manchete, algo me chamou a atenção, algo sobre o qual eu nunca escrevi, mas que de alguma maneira desafiava minha imaginação sociológica. Era basicamente o seguinte: como as telenovelas brasileiras podiam ser exportadas com um relativo êxito? A primeira coisa que você se dá conta é de que as telenovelas brasileiras não são exportadas integralmente, elas são compactadas. Aquela "famosa" telenovela, A Escrava Isaura, não foi vendida com seus 200 capítulos. As telenovelas são exportadas para a Europa com cerca de 80 capítulos, as vezes menos. Portanto, o que intrigou foi: como reduzir uma telenovela com 200 capítulos, para 80, 60, 40 capítulos? Quais os critérios utilizados neste tipo de operação? A resposta que obtive foi: tudo o que é supérfluo deveria ser cortado. Mas o que é supérfluo? Novamente a explicação que me deram foi, supérfluo é tudo que é demasiadamente local, brasileiro. Isso significa que uma telenovela quando é exportada, muito do que apreciamos, do que consideramos como "autênticamente" nacional é eliminado no corte, inclusive a própria música é substituída por uma trilha sonora mais "internacional". O que é mais interessante é que esta compactação não é feita, nem supervisionada, pelo autor da novela, por nenhum dos seus diretores e sem nenhuma participação dos atores. Quem realiza esta operação é um técnico no isolamento de sua sala de edição. Mas como ele pode "cortar tão bem"? Para isso há uma resposta plausível: ele atua segundo um padrão estético "internacional popular", um padrão do qual ele participa inconscientemente, que faz parte de sua vivência. Isso me levou a perguntar quais são as instâncias de produção de um gosto mundializado. Se entendermos, como coloca muito bem Pierre Bourdieu, que o gosto não é algo apenas subjetivo, mas social, a pergunta transforma-se imediatamente num objeto heurístico de pesquisa. Meus estudos sobre a mundialização iniciaram-se com esse questionamento num momento em que poucas pessoas estavam interessadas no tema. Lembro que na época predominava no debate a polaridade modernidade versus pós-modernidade e não a temática da globalização.

\section{Identidade Cultural}

NO - A temática da mundialização da cultura faz retomar a indagação sobre a identidade cultural, uma questão sempre presente na análise da diversidade cultural do mundo contemporâneo.

RO - Toda discussão sobre identidade nacional está vinculada a um debate sobre a emergência da nação. A rigor, o Estado-nação não tem mais de 200 anos. Portanto, a preocupação em tomo das identidades nacionais, sejam elas, brasileira, francesa, norte americana, 
evolui dentro deste período. O processo de globalização da economia, da tecnologia, e a mundialização da cultura, coloca em causa a autonomia do Estadonação. Isso significa que o estado nacional já não tem mais a capacidade de gerar uma identidade convincente para o conjunto da população contida em seu território. Nesse sentido, é que vamos ter, e já estamos assistindo, a uma fragilização das identidades nacionais. Significa dizer que elas vão acabar? Não, da mesma maneira que o Estado-nação não termina com o processo da globalização. Significa porém que um conjunto de outras instâncias, de forças recentes, que não fazem necessariamente parte do Estado-nação, têm cada vez mais um peso importante. A debilitação do Estado-nação não coincide pois com o seu desaparecimento (existem exército, polícia, burocracia, políticas públicas, políticas públicas sociais, etc). O grande dilema é que ele é hoje um ator entre outros, perdendo a centralidade que possuía até então. Se recuássemos no tempo, 20, 30, 40 anos atrás, com um certo otimismo poderíamos dizer que os problemas brasileiros poderiam ser equacionados dentro do quadro do Estado-nação Brasil. Atualmente não temos essa mesma certeza pois um conjunto de forças transnacionais que atravessam o território nacional, já não mais coincidem com os interesses do estado nacional. Dentro desse contexto, não temos o controle, o poder de ditarmos o nosso destino, o que é dilacerante. Os europeus enfrentam também a mesma situação, só que a partir de uma outra inserção mundial, e com um outro projeto político, o que o situa de maneira muito mais favorável no mundo contemporâneo. Eles estão construindo um espaço territorial supranacional com mais possibilidades de poder e controle, coisa que nós desconhecemos. No debate sobre a globalização não há necessidade de operarmos com a idéia de desaparecimento do Estado-nação, ou de contrapormos, como se tratasse de coisas contraditórias, as identidades nacionais ou culturais ao movimento de globalização. Não existe um movimento de transnacionalização por um lado e de "balcanização" das identidades por outro, como se vivemos num mundo esquizofrênico. Trata-se de um mesmo movimento, de um mesmo mundo, no qual as diferenças e as desigualdades das identidades se expressam no contexto da modernidade- mundo.

A identidade nacional é sempre uma construção simbólica na qual as forças culturais, sociais e econômicas, enfim, os interesses, atuam das mais diversas formas. Construção simbólica que se realiza de maneira diferenciada em função da história real e imaginada de cada país. Temos no Brasil mais de um século de discussão sobre a questão nacional. Mas a questão não é tanto definir, como no passado tentaram diversos autores, qual seria a "autêntica" identidade brasileira. Sei que ainda existem autores que acreditam na existência “do brasileiro”. Não penso assim, para mim faz pouco sentido falar "no brasileiro", "no japonês", "no americano". O que temos é um processo de construção das identidades, processo tecido pela história dos lugares e pelos distintos interesses nela envolvidos. Por isso a resposta que se dá à pergunta "o que é ser brasileiro", "o que é o japonês", varia ao longo do tempo. $\mathrm{Na}$ verdade parece-me um tanto insensato nos perguntarmos se as identidades construídas são autêntica ou não. Se elas se transformam, não é porque deixam de ser verdadeiras e passam a ser falsas, ou vice versa, passam de falsas a verdadeiras. As identidades estão sempre em constante transformação. O que muda com a globalização é que o processo de construção das identidades nacionais toma-se mais complexo pois entram agora em jogo forças que extravasam as fronteiras nacionais. O dilema atual rebate-se assim sobre a própria idéia de projeto nacional. A inserção do Brasil no mundo globali- 
zado é subalterna. Se tivéssemos a esperança de podermos construir um projeto nacional autóctone, teríamos uma janela de "salvação" pelo menos entreaberta. Infelizmente não acredito nisso, e o digo com pesar. Não neste século XXI no qual o Estado-nação se fragilizou. Vocês poderiam perguntar quais janelas estariam então abertas. Sinceramente, não tenho resposta para isso.

\section{Espaço Público}

NO - A expansão generalizada das tecnologias de comunicação e informação criam um novo cenário de interação real e simbólica da vida social. Estaríamos diante de uma nova configuração de espaços públicos? Uma nova dimensão de democracia?

RO - Nessa discussão sobre o espaço público é preciso distinguir as coisas. A noção de espaço público vincula-se à questões como, igualdade, democracia, liberdade. Esses são valores centrais na argumentação de um autor como Habermas. Se não existe democracia, liberdade e igualdade, não há um espaço público inteiramente materializado enquanto lugar de debate, diálogo e conflito. Qual seria a relação entre esta esfera social e a técnica, ou melhor, as tecnologias que atuam em seu interior? Uma visão pessimista diria que não há possibilidade de atuação crítica e política num espaço no qual a técnica é determinada pelos interesses mercadológicos. Outra visão, mais otimista, vê nas "novas tecnologias" (um pouco como faz Pierre Levy) uma nova dimensão da democracia, o que é um exagero. Creio que a resposta correta dependerá dos homens vivendo em sociedade, de seus interesses, de suas políticas. A tecnologia não existe em si, como muitas vezes se acredita, ela é permeada pelo social e pelo cultural. Nelas não está inscrito que sejam necessariamente alienantes ou libertárias. Evidentemente as tecnologias não operam no vazio, elas são objetivamente marcadas pelas desigualdades sociais, pelas hierarquias existentes entre países ricos e pobres, pelos interesses econômicos. Abstrair este quadro seria pura ingenuidade. No entanto, não creio que exista um espaço público monolítico (aliás não penso também que exista um espaço público ideal, de uma certa forma a proposta de Habermas é uma utopia, no bom sentido da palavra). Existem potenciais ou espaços de potencialização para uma atuação critica. É no jogo de contraste entre o lado objetivo (cruel, mercadológico, restritivo) do presente e a abertura do futuro (o que se pode fazer) que se insere o lugar da crítica e de uma ação transformadora.

Eu diria ainda que num mundo globalizado, com as tecnologias que conhecemos a noção de pertencimento se transforma, inclusive as identidades nacionais ou particulares. Não há dúvida que as tecnologias de transmissão de dados , de interação, modificam o horizonte da ação social. No mundo contemporâneo, com a desterritorialização e reterritorialização do espaço, as noções de pertencimento, próximo e distante, familiar e estranho, se transformam. A questão é saber se essas mudanças estão necessariamente vinculadas a um ganho na esfera pública reforçando valores como democracia, participação e liberdade. Tenho a impressão que isso está longe de ser verdadeiro, se é que um dia o será.

\section{Estudos Culturais e Comunicação}

NO - Os estudos sobre comunicação social no Brasil e em diversos países da América Latina - especialmente quanto à recepção - foram revigorados desde os anos 80 com a contribuição dos estudos culturais, em sua vertente inglesa. Como avaliar essa contribuição?

RO - Quando estive na Escócia, na universidade de Striling, juntamente com o Jesus Martín-Barbero e Nestor Garcia Canclini, um pouco como um dos representantes dos "estudos culturais" na América Latina, a primeira coisa que disse foi "não sei o que são estudos culturais". Afinal muito antes que eles 
existissem enquanto área de estudo eu já vinha trabalhando nessa direção. Não só eu. Há uma tradição na América Latina, cultivada por diversos autores que seguramente poderia ser classificada como de estudos culturais. Eu tenho uma certa dificuldade em aceitar o termo "estudos culturais". Talvez por que não acredite que a denominação seja suficiente para delimitar uma área de saber. Na verdade, o que temos em toda América Latina é um estudo da esfera cultural, que podemos chamar de sociologia da cultura, antropologia, estudos literários, comunicação, que entre nós se desenvolveu de maneira distinta do que ocorreu nos Estados Unidos ou na Inglaterra. Essa tradição combina desde questões econômicas, políticas, sociais e culturais, numa espécie de encruzilhada, de ponto de encontro inter-disciplinas. Talvez, no caso brasileiro, e de boa parte da
América Latina, isso tenha sido fruto da especialização tardia das Ciências Humanas. Por exemplo, no Brasil a Sociologia somente se autonomiza, para falarmos como Bourdieu, nos anos 50. A institucionalização da Ciência Política é ainda mais tardia, data dos anos 70 . Por isso é recorrente na produção intelectual latino-americana a mescla de fronteiras, como se as disciplinas tivessem dificuldade em erigir barreiras definitivas entre um tipo de abordagem e outro. No caso dos Estudos Culturais da América do Norte e da Inglaterra o panorama é o inverso. Aí as fronteiras são bem delimitadas e zelosamente defendidas por seus integrantes. Neste contexto os chamados estudos culturais surgem com uma proposta "nova", isto é, na qual a interdisciplinaridade se contrapõem ao enrijecimento das fronteiras disciplinares.

\section{Bibliografia do entrevistado}

- A morte branca do feiticeiro negro: umbanda e sociedade brasileira. Ed. Vozes, Petrópolis, 1978.

- A consciência fragmentada. Ed. Paz e Terra, Rio de Janeiro, 1980.

- Pierre Bourdie. Ed. Ática, São Paulo, 1983.

- Cultura brasileira e identidade nacional. Ed. Brasiliense, São Paulo, 1985.

- A moderna tradição brasileira. Ed. Brasiliense, São Paulo, 1988.

- (em co-autoria com BORELLI, Silvia H. S. e RAMOS, José M. O.) Telenovela, história e produção. Ed. Brasiliense, São Paulo, 1989.

- Românticos e folcloristas. Ed Olho d'Água, São Paulo, 1992.

- Mundialização da Cultura. Ed. Brasiliense, São Paulo, 1994.

- Um outro território: ensaios sobre a mundialização. Ed. Olho d'Água, São

Paulo, 1996.

- Los Artífices de una Cultura Mundializada. Siglo dei Hombre Editores, Bogotá, 1998. 